commenting on certain alleged facts quoted in an ethnological article in Citssell's Popular Educator, from Dr. Theodor Waitz's "Introduction to Anthropology," translated by Mr. Collingwood. Mr. Field justly remarks that facts of such a character, " if substantiated, would introduce Accidental Distortion as a coworker with Natural Selection in the modification of species." But he puts the question- "Do these stories rest on a good foundation?" Personally, I do not know. All I can say is, that Dr. Waitz, whose scientific authority is unimpeachable, published them without expressing any doubts of their accuracy. They may be found with some alleged facts of analogous character, at pp. 83 to 85 of his first volume, as translated by $\mathrm{Mr}$. Collingwood. Speaking of animals, he says :-

"Mutilations also are sometimes transmitted. Williamson* saw in Carolina dogs which have been deficient in tails for three or four generations, in consequence of one of their ancestors having accidentally lost it. A cow, three years old, which had lost by suppuration her left horn, produced three calves, which, instead of the left horn, presented only a small protuberance on the skin. Dogs and horses whose tails or ears are clipped, as the draught dogs in Kamtschatka, often transmit these deficiencies to their offspring." (p. 83.)

Referring next to man, he considers that there are "cases in which deformities have shown themselves hereditary" (p. 84.) He says :-

"Instances of hereditary blindness and deafness, and of alternating dumbness, so that every second or third child was deaf, are given by Lucas. Harris communicates a case of hereditary, blindness in one eye, and of a double thumb on the right hand."

I omit other instances. He continues again :-

"Instances are not wanting of mutilations that have been transmitted from parents to children; such, however, occur less frequently. According to Blumenbach, the children of an officer, whose little finger had been cut across and become crooked, possessed an analogons defect. Gosse cites the case of an officer wounded in the battle of Eylau, who transmitted to his offspring a scar on the forehead. Other instances of hereditary deformities are found in Wagner" (p. 85 ).

As Waitz, it will be perceived, quotes Blumenbach, it may be mentioned that the last-named author has a paragraph headed, "Problem proposed. Can mutilations and other artifices give commencement of native varieties of animals?" After showing that some have answered the question in the affirmative and others in the negative, he adds, "I have not at present adopted as my own either the affirmative or negative of these opinions." See p. 203 of his Anthropological Treatises, translated by Mr. Bendyside.

New facts, capable of being severely tested, would be of great value.

The Writer of the Ethnological Papers IN "CASSEll's Popular EduCator"

\section{The Stability of Turret Ships}

SINCE the loss of the Captain an opinion has rapidly gained ground, not only amongst unscientific men, but even amongst those who from their education should have acquired some of the most simple laws of statics, that that noble ship toppled over on account of her being "top-heavy"-that the Captain, an armour-plated ship with a low freeboard, was more "topheavy" than a broadside ship, with more than twice as much out of water! The fact is, that her weights were lower and not higher than those of other vessels, and therefore that her fault was not "top-heaviness."

In looking at the stability of a vessel we take two points-the "centre of gravity" and the "centre of buoyancy;" the former being a certain point at which, if the attraction of gravity impressed a single force equal in intensity to the sum of all its separate actions on the component parts of the body, the ultimate effect would be the same as it is under the system of separate actions which really exists. The latter is the centre of gravity of the volume of water displaced by the ship, and may be regarded as the pivot on which she would turn on heeling over. The vessel being in a vertical position, the centre of gravity is immediately over the centre of buoyancy, and she is in a state of unstable equilibrium, i.e. she is in the same fix as a walkingstick standing on end. So far in favour of "top-heaviness."

* More specific reference to the authorities on which Waitz rested may be found in the foot-notes to his work. Some of the volumes he quotes are foreign, and not to be found in the Pritish Muscum Library.
Suppose now that she heels over to one side, what will the effect on our centres be? Immediately she begins to heel over the centre of buoyancy travels outwards to the side towards which she heels, and the centre of gravity being fixed, there will come a point when it will exert a force to overcome the heeling over pressure. This travelling outwards of the centre of buoyancy depends wholly on the shape of the vessel, and will appear perfectly plain by drawing slietches of a ship lying at different angles. The more a vessel heels over, the further outwards does the centre of buoyancy travel, and the greater is the resistance offered to the heeling over pressure until she approaches a certain point, then the centre of buoyancy moves out at an increasingly slower rate, and finally reaches the position corresponding to that of her maximum statical stability.

Before this, if by any disturbing cause, such as the alteration of the wave slope, the ship were inclined beyond her position of maximum stability, the resistance to heeling would become less the farther she went, until she reached a position at which her moment of stability would be the same as before the disturbing force began to act. And in this position she would remain in unstable equilibrium if the disturbing forces were removed. But if she should pass this position before the disturbing forces, and the angular velocity caused by them, cease, the ordinary movement of the heeling over force would then be greater than the resistance offered by the stability, in any position through which she would pass, and she would be turned over.

Now the difference between a high and a low freeboard ship as regards stability under sail is this :- - The position of maximum stability is reached soon after the immersion of the edge of the deck; and as a high freeboard ship does not immerse her deck until she has attained a large inclination, while a ship of low freeboard will immerse hers at a very much less angle, it follows that, in the latter case, the position of maxinum stability and then of unstable equilibrium is reached at a comparatively small angle of heel, and a ship of this construction is much more likely to be capsized than one with a high freeboard. Of course, in a low-sided ship, the centre of gravity may be brought so low as always to be on the right side of the centre of buoyancy, but this is not practicalble in an armour.plated turret ship.

From what we have here stated it will be seen that the etror in design that made the Captain so much heavier than was expected, and draw six fe $t$ instead of eight, was not adding so much to her stability but was in reality lessening it, and, perhaps, was the cause of her loss; and that if we are to have armour-plated turret ships, they must either be built of low freeboard, to be propelled by steam alone, or of high freeboard sufficient to give stability for sails.

The feud hetween naval architects and the advocates of the turret system has been going on for ten years back-the former contending that a high side was necessary in a rigged sailing ship, and the latter, that if they put their guns in turrets, they could have low-sided ships, or, in fact, ships with no sides at all, after a certain anount of inclination.

That the loss of the Captain has resulted from a preventible cause is quite evident, and we have shown what that cause is; it, therefore, only remains that if we are to have sailing turret ships, we must have high freeboard for the sake of stability.

Newcastle-upon-Tyne

T. BELL LIGH'YOOT

\section{The New Postal Act}

AT page $474 \mathrm{Mr}$. Reeks complains as to the working of the new Postal Act. It seems intended to obliterate the old parcel post. He says," "Herbarium specimens are not excluded." Perhaps so ; but they are not included. The provisions of the new Act are limited to books, written and printed matter, genuine trade samples and patterns, so far as regards the two ounces for a halfpenny. All parcels other than books, \&c. as described above, go at the letter rate of one penny for each half-ounce.

The postal card is the thin end of the wedge that will hereafter open to us a regular letter rate of a quarter of an ounce for a halfpenny. For instance: we may now send ordinary business commurications up to two ounces, thus embodying the matter of twenty postal cards, for the halfpenny, if folded in a paper wrapper. An ordinary business communication of half-ounce weight goes for the halfpenny, if folded as a letter but left unsealed.

I ask, If Government will now take an open ?etter for a halfpenny, why not take it closed at the same rate? Common sense 